\title{
Economic Modeling of Water Need Determination in Lebanon: Implication for Lebanon's Agriculture
}

\author{
Bassam Hamdar ${ }^{1, ~ *, ~ A b b a s ~ H a m d a n ~}{ }^{2}$ \\ ${ }^{1}$ Department of Economics, Faculty of Business and Economics, American University of Science and Technology, Beirut, Lebanon \\ ${ }^{2}$ Master of Business Administration (MBA) Program, Faculty of Business and Economics, American University of Science and Technology, \\ Beirut, Lebanon
}

Email address:

bhamdar@aust.edu.lb (B. Hamdar)

${ }^{*}$ Corresponding author

\section{To cite this article:}

Bassam Hamdar, Abbas Hamdan. Economic Modeling of Water Need Determination in Lebanon: Implication for Lebanon's Agriculture. American Journal of Water Science and Engineering. Vol. 6, No. 1, 2020, pp. 31-38. doi: 10.11648/j.ajwse.20200601.14

Received: September 26, 2019; Accepted: January 31, 2020; Published: February 11, 2020

\begin{abstract}
The Arabian orient from the end of World War II on has been boiling with conflicts, the underlying reason ever since, natural resources. The vassal states created by the French and the British after their victory in the Great War had their borders drawn on the premise of distributing this wealth. However; priorities in the region are starting to shift. With the rising prices, diminishing reserves of oil and the discovery of larger deposits in other regions of the world, the dependence on solar and renewable energy sources is gaining an equivalent strategic importance, water is becoming a major player in the region's politics, and it is the new strategic asset. Whether in energy production or agriculture, water, is a more suitable substitute to produce electricity at lower costs, a perfect substitute to oil and gas, and safer than nuclear energy. This paper aims at revealing the wasted wealth of water that Lebanon has thirsty neighbors look upon to have. Lebanon is a small piece of land, which God almighty has blessed with annual rain that averages between 8 to 10 billion $\mathrm{m}^{3}$, a figure that can easily classify as a strategic asset. The regions` limited fresh water resources will determine the future political alliances and will possess the key to trigger wars. This paper also demonstrates how the increase in agricultural production would lead to an increase in water needed for irrigation that varies according to the nature of the crops considered by this study i.e., Wheat, Veggies, Citrus, and Apples. The Ordinary Least Squares (OLS) method was utilized to determine the needed water per crop per ton. A regression model with four independent variables was used to cover Wheat, Veggies, Citrus, and Apples, along with one dependent variable, the level of water needed. The findings indicated that for every ton of wheat produced 14 MCM of water is needed, and for every ton of veggies produced $0.002 \mathrm{MCM}$ of water is needed, moreover, for every ton of citrus produced $0.006 \mathrm{MCM}$ of water is needed, and finally, for every ton of apple produced $0.035 \mathrm{MCM}$ of water is needed.
\end{abstract}

Keywords: Lebanon, Water Resources, OLS Method, Needed Water Per Crop. Agriculture

\section{Introduction}

Water is the source of all living things. Throughout all phases of human history civilizations have thrived near and around water resources. Conflicts have always erupted to maintain control over and access to water sources. The ancestors of the Arabs came from Yemen, with a flourishing kingdom, the famous kingdom of Saba, they thrived around water resources. According to historians, the kingdom collapsed when the famous damn, Marib Dam, collapsed, the population dispersed into the desert to the north, of nowadays
Yemen [1]. One of the oldest cities of the world, over 7000 years old, Byblos (figure 1), was founded around water well. The Pharaohs, the Numidians, and the Ethiopians were great civilizations, what they had in common was the water of the Nile. They came to life and thrived on its river banks.

Survival of all species is procured through water. Its abundance has led communities to take it for granted. Whatever humanity achieved would not have been possible if this simple, yet vital commodity has not been available.

The prosperity of the Arabian Orient and augment of its population during ancient history was a direct outcome of the abundance in food commodities, ranging from vegetation to 
livestock. An abundance that was a direct outcome of the availability of water resources combined with proper utilization and advanced irrigation methods. A famous example is the Saba Kingdom, "Saba's capital was at Marib, a town located in an intensively cultivated area watered by a large reservoir. This reservoir, stacked up behind a dam near the town, was the central feature of the kingdom's irrigation system; it was this which made productive agriculture, and with-it urban civilization, possible [1].

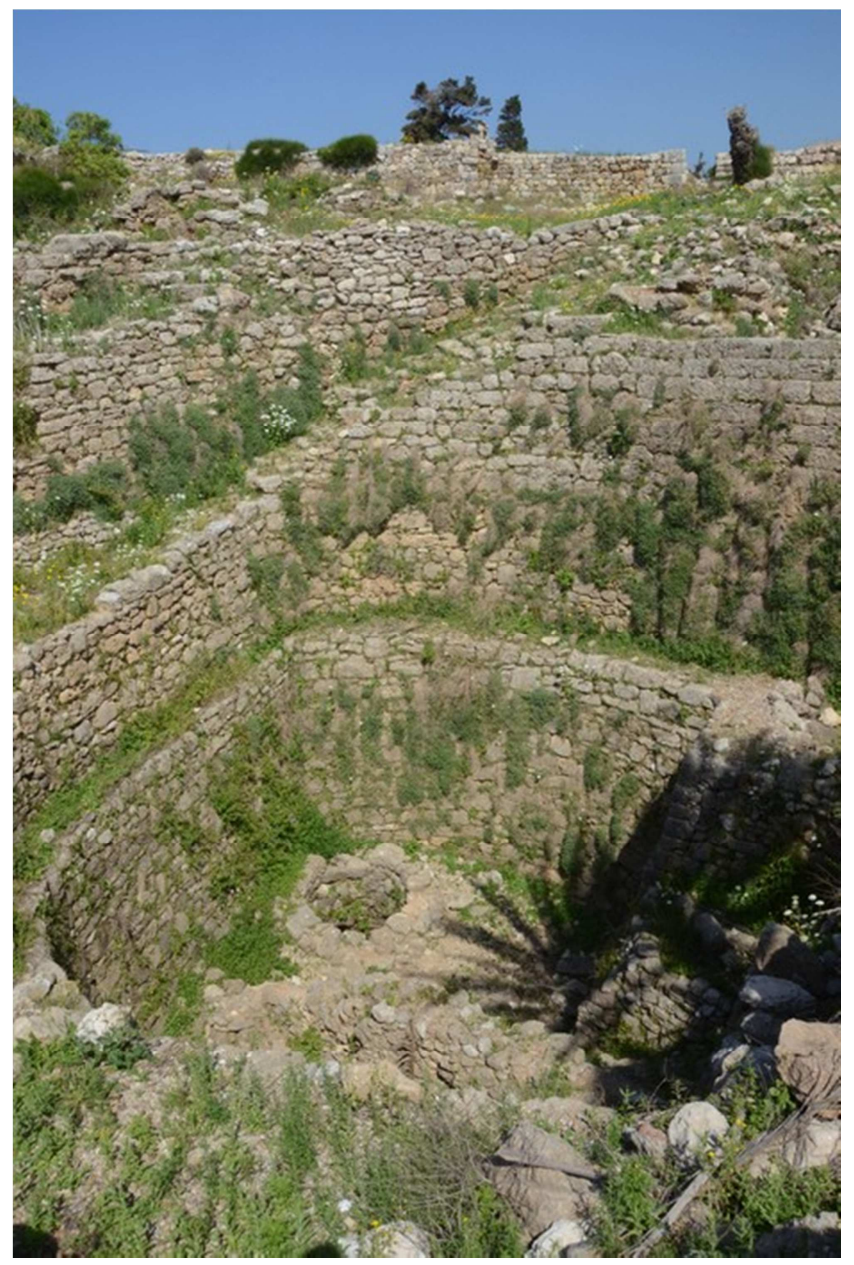

Figure 1. Byblos Well the point where the city was born 7000 years BC [2].

From agriculture stems the importance of using waste water, considering the challenges posed by the constant rise in the world population, expected to reach 9.80 Billion in 2050 [3]. The domestic demand driven by the increase in population is also expected to increase, not to forget the agricultural sector; currently consuming $70 \%$ of all water withdrawn [4].

With the increasing domestic demand for fresh water, a perfect alternative to be used that can reduce pressure on available sources that are already overstretched is recycled waste water [5]. Recycled water can be used as a substitute in landscape irrigation, public cleaning, agriculture sector, livestock, toilet and urinal flushing, industrial processing, wetland habitat creation, restoration, maintenance and recharge of underground reservoirs [6].

\section{Water sources}

Lebanon is a water bank with multiple advantages in location and terrain. The country`s mountain range of 2200 meters above sea level, and with a longitude of 170 kilometers overlooking the Mediterranean, provides a geographic wealth. The current location provides the necessary conditions to contain atmospheric pressure moisture, which in turn leads to heavy rain and snow in the winter season [7].

Another wealth that lies within Lebanese mountainous terrain is the geology. Composed of dolomite calcite rocks, a geological layer, perfect for absorbing and storing water, (figures 2, 3 and 4). It absorbs and stores in under layers, creating undersurface lakes that in turn, overflow on the surface in forms of springs and rivers. Out of the nation's rivers, 14 of which flow year-round during all four seasons which Lebanon is famous for [8].

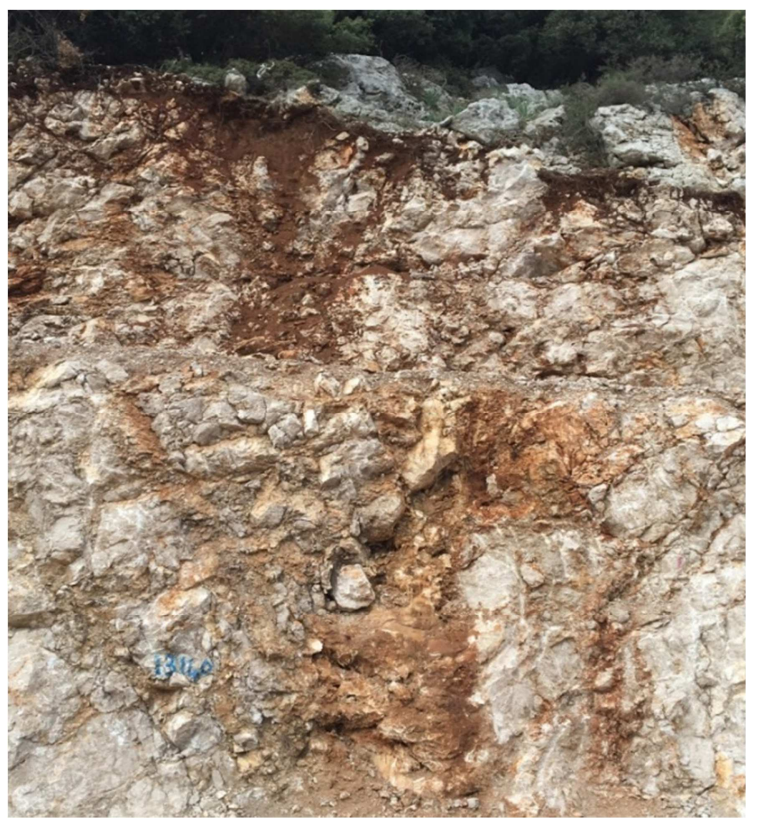

Figure 2. Picture showing the side of an excavated mountain [2].

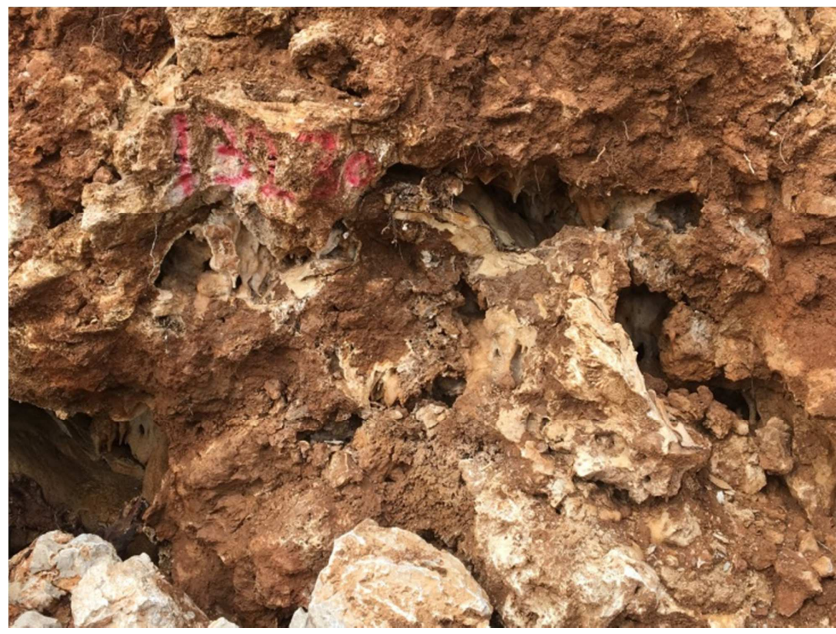

Figure 3. Camera focusing on one the mountain to show inner formations [2]. 


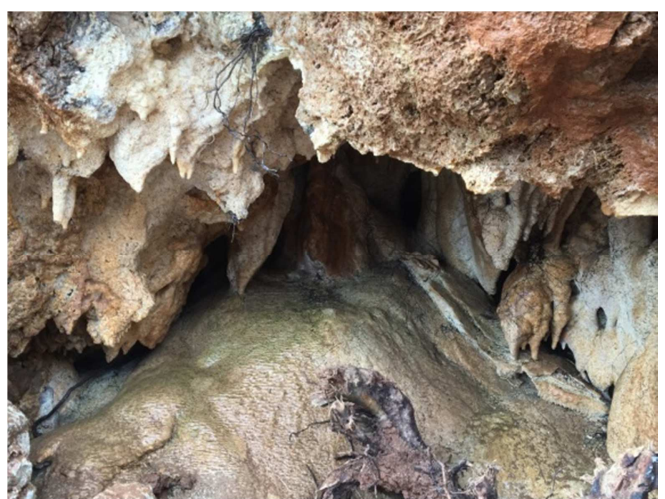

Figure 4. Water passage ways to underground lakes [2].

The above pictures have been taken form a study that was carried out on December $23^{\text {rd }}, 2018$, during the construction works on the highway from Nahr (Nahr Means River in Arabic) Ibrahim north of Lebanon to the mountain villages. During the excavation works, live evidence on the importance of the geology and the active role nature plays in replenishing the underground lakes and aquifers, was revealed.

Lebanon has 8 acquihires, 17 river basins fed by over 2000 springs that are evenly distributed over the national territory [9] Ministry of Water and Electricity (MOWE) and United Nations development program (UNDP) depicted 5,050 springs.

The country hydro stratigraphic units are of three groups: aquifers, semi-aquifers and aquicludes. The two major aquifers are Kesrouane Jurasic and Sannine Maameltin, both cover about $5590 \mathrm{~km}^{2}$ of the Lebanese territory [10].

Unplanned exploitation of underground water through licensed wells and unlicensed digging of wells, has led to a resource stress in Lebanon. Regional Overview of Arabian Orient and North Africa indicates the fact that water disputes are inevitable, specifically, in the Middle East [11].

\section{Literature Review}

\section{Water Collection}

Having uneven terrain, mostly mountainous with hills and valleys, artificial collection structures for collecting rain and flood water can be constructed all over Lebanon [12]. Millions of liters could be collected all over Lebanon. Construction of artificial water collection structures is extremely beneficial and efficient in terms of cost. These structures do not necessitate costly or complicated engineering works. All that is required is simple adjustments to the terrain at the hill tops, valleys, and natural rainfall and melting snow collection points. Adjustment could be expansion of natural collection points, excavation works at plains surrounding hill tops to create artificial lakes and reservoirs [13].

The most suitable locations for the above-mentioned projects would be the Western slopes. According to Houri et al. 2007, "A significant portion falls of the rain falls on the western slopes, ranging from $892 \mathrm{~mm}$ on the coast and reaching $1210 \mathrm{~mm}$ at higher altitudes".

Rainwater Harvesting

The major reason for the stress on water reserves is due to weakness in replenishments.

Rain harvesting is a major advantage that can be used to solve many of the current water sector problems. This approach can be a combined effort between the public and the private sectors [7].

What is Rain harvesting and how it works?

Rainwater harvesting is the process of accumulating, treating and storing rainwater for reuse [14]. The water from rain is collected from roofs of buildings and houses through a rainfall catchment system. The catchment system is the simple water drainage with pipes already installed on rooftops. The only adjustment required is the additional pipes necessary to deliver the water to underground water tanks.

\section{Research Methodology}

Regression Analysis

Regression Analysis is a statistical tool with a set of statistical processes that is used for estimating the relationships among specific variables. The variables are of two groups, dependent (water demand...) and independent (agricultural produce...). Regression analysis is used to understand which among the independent variables are related to the dependent variable by measuring the changes in the dependent variable based on the change in the independent variables, it is a measure of the cause and effect relationship between dependent and independent variables, that is; probable change in one variable for the given amount of change in another. In addition to cause and effect it can be used to predict trends and future values and to get point estimates [15].

The Equation of the Regression Analysis is:

$$
\mathrm{Yi}=\alpha+\beta \mathrm{Xi}+€_{\mathrm{i}}
$$

i: number of observations

$\alpha$ : intercept of the model

$\beta$ : slope

$€_{i}$ : random errors of the observations

Xi: observed score on the independent variable

Yi: observed score on the dependent variable

Regression Analysis on the need for Irrigation water:

The parameters used in this paper are: Years, the water need, and agricultural produce in Tons. The figures for each parameter are presented in Table 1 below.

The water need model is made up of four parameters i.e.

$$
Y=\beta_{0}+\beta_{1} X_{1}+\beta_{2} X_{2}+\beta_{3} X_{3}+\beta_{4} X_{4}+€_{i}
$$

Where:

$\mathrm{X}_{1}$ : Is the yearly production of Wheat in tons

$\mathrm{X}_{2}$ : Is the yearly production of Veggies in tons

$\mathrm{X}_{3}$ : Is the yearly production of Citrus in tons

$\mathrm{X}_{4}$ : Is the yearly production of Apples in tons

$€_{\mathrm{i}}$ : The error term or the scholastic disturbance of the 
model.

Table 1. The dependent and independent Variables.

\begin{tabular}{lllll}
\hline Year & $\begin{array}{l}\text { Water Needed } \\
\text { (Dependent Variable) }\end{array}$ & $\begin{array}{l}\text { Wheat production in } \\
\text { tons }\end{array}$ & $\begin{array}{l}\text { Veggies production in } \\
\text { tons }\end{array}$ & $\begin{array}{l}\text { Citrus production in } \\
\text { tons }\end{array}$ \\
\hline 2006 & 10,130 & 153,400 & $1,160,600$ & 374,200 \\
2007 & 9,835 & 116,200 & $1,300,600$ & 392,500 \\
2008 & 9,548 & 105,700 & 976,200 & 343,000 \\
2009 & 9,270 & 11,400 & $1,057,000$ & 364,400 \\
2010 & 9,000 & 83,522 & $1,106,054$ & 247,020 \\
2011 & 8,730 & 86,834 & $1,093,536$ & 232,199 \\
2012 & 8,468 & 84,229 & $1,081,159$ & 218,267 \\
2013 & 8,214 & 81,702 & $1,068,922$ & 205,171 \\
2014 & 7,968 & 80,068 & $1,056,824$ & 1300 \\
2015 & 7,729 & 78,467 & $1,044,863$ & 192,860 \\
2016 & 7,497 & 76,898 & $1,033,037$ & 180 \\
2017 & 7,272 & 75,360 & $1,021,345$ & 1,289 \\
2018 & 7,054 & 73,853 & $1,009,786$ & 1700 \\
\hline
\end{tabular}

\section{Results and Findings}

The Hypothesis of this paper will test the effect of agricultural production on the Water Needed. The Impact is expected to be positive, that is; as the production increases the demand for water is expected to increase.

The main question of the hypothesis is: By how much the Need for Water will increase for each increase per tons of agricultural produce?

The below equation will explain the relationship between the four variables:

$$
\mathrm{WN}=\beta_{0}+\beta_{1} \mathrm{WHT}+\beta_{2} \mathrm{VEG}+\beta_{3} \mathrm{CIT}+\beta_{4} \mathrm{APP}+\epsilon_{\mathrm{i}}
$$

All the variables in the above equation, their definitions, unit of measurement, and data sources are presented in table 2 below.

Table 2. Variables and data Sources.

\begin{tabular}{|c|c|c|c|c|c|}
\hline & Label & Variable & Definition & Unit of Measurement & Source of Data \\
\hline 1 & WN & Dependent & Water Needed for Irrigation & $\mathrm{MCM}$ & MOEW \\
\hline 2 & WHT & Independent & Production of Wheat & Ton & MOA \\
\hline 3 & VEG & Independent & Production of Veggies & Ton & MOA \\
\hline 4 & CIT & Independent & Production of Citrus & Ton & MOA \\
\hline 5 & APP & Independent & Production of Apples & Ton & MOA \\
\hline
\end{tabular}

The data for the variables was collected from two sources; Ministry Of Energy and Water (MOEW), and Ministry Of Agriculture (MOA), covering the period of 2006 to 2018.

Analysis and Findings

The methodology used in the paper revolves around the Water
Need (WN) Model. The techniques applied investigate the variations in $\mathrm{WN}$ as a result of the changes in the four independent variables. The result of the $\mathrm{WN}$ model is shown in table 3 . The table is a combination of three tables, the Coefficient table, the ANOVA table, and the model summary table.

Table 3. Ordinary Least Squares Estimation of the WN Model.

\begin{tabular}{|c|c|c|c|c|}
\hline \multicolumn{5}{|c|}{ Dependent Variable is WN } \\
\hline Parameters & Coefficient & & Standard Error & T-Ratio [Prob.] \\
\hline Constant (CON) & $\beta_{0}$ & -660.922 & 1617.749 & -0.409 \\
\hline Wheat & $\beta_{1}$ & 0.014 & 0.006 & 2.231 \\
\hline Veggies & $\beta_{2}$ & 0.002 & 0.001 & 1.754 \\
\hline Citrus & $\beta_{3}$ & 0.006 & 0.002 & 3.645 \\
\hline Apples & $\beta_{4}$ & 0.035 & 0.009 & 4.082 \\
\hline R-Squared & 0.97 & R-Bar Squared & & 0.97 \\
\hline Mean of WN & 8516.38 & Residual Sum of Squares & & 355541.4259 \\
\hline Durbin Watson & 2.833 & Regression sum of squares & & 11639750.25 \\
\hline VIF Wheat & 5.592 & Tolerance Wheat & & 0.179 \\
\hline VIF of Veggies & 1.544 & Tolerance Veggies & & 0.648 \\
\hline VIF of Citrus & 6.231 & Tolerance Citrus & & 0.160 \\
\hline VIF of Apples & 1.266 & Tolerance Apples & & 0.790 \\
\hline
\end{tabular}

According to the table above, the regression equation has the following form:

$$
\mathrm{WN}=-660.992+.014 \mathrm{WHT}+.002 \mathrm{VEG}+.006 \mathrm{CIT}+.035 \mathrm{APP}
$$

The equation reveals that if:

$\beta_{0}=$ is the intercept of the model, it indicates the value of the needed water when all the crops are at a level of Zero

$\beta_{1}=$ Slope of the model according to WHT indicates that 1 
unit change in WHT leads to 0.14 units of change in WN. The interpretation of the information is that, increasing production of Wheat by one ton will lead to an increase for the Water Needed by 0.14 MCM.

$\beta_{2}=$ Slope of the model according to VEG indicates that 1 unit change in VEG leads to 0.002 units of change in WN. The interpretation of the information is that increasing production of Wheat by one ton will lead to an increase for the Water Needed by 0.002 MCM.

$\beta_{3}=$ Slope of the model according to WHT indicates that 1 unit change in WHT leads to 0.006 units of change in WN. The interpretation of the information is that increasing production of Wheat by one ton will lead to an increase for the Water Needed by $0.006 \mathrm{MCM}$.

$\beta_{4}=$ Slope of the model according to WHT indicates that 1 unit change in WHT leads to 0.35 units of change in WN. The interpretation of the information is that increasing production of Wheat by one ton will lead to an increase for the Water Needed by 0.35 MCM.

After testing for correlation coefficient, it is important to test for multicollinearity. Multicollinearity in a model signifies that the independent variables are highly correlated, which can lead to unstable regression coefficients. To test for multicollinearity two measures are used:

Variance Inflation Factor (VIF) a measure of how much correlation exits between the independent variables. The value of VIF should be below 10 [16].

Tolerance is estimated by $\left[1-\mathrm{R}^{2}\right]$. The minimum level of tolerance should be greater than 0.1 [17].

The Analysis as in the above table reveals that the model has no Multicollinearity because VIF is less than 10 (VF < 10) and the Tolerance is greater than 0.1 (Tolerance $>.01$ ).

The next concern is whether each individual variable is statistically significant or not. This relies on the t-test in the above table.

$$
\text { 1. } \begin{array}{r}
H_{0}: \beta_{1}=0, \beta_{2}=0, \beta_{3}=0, \beta_{4}=0 \\
H_{1}: \beta_{1} \neq 0, \beta_{2} \neq 0, \beta_{3} \neq 0, \beta_{4} \neq 0
\end{array}
$$

2. $\alpha=0.05$

3. The decisive hypothesis for the t-test hypothesis is as follows:

a. If $\mathrm{t}^{*} \leq \mathrm{t}$ (critical or tabulated $\mathrm{t}$ ) conclude that $\mathrm{H}_{0}$ such that there is no relation between the dependent and the independent variable under consideration.

b. If $\mathrm{t}^{*}>\mathrm{t}$ (tabulated or critical value) conclude $\mathrm{H}_{1}$ and reject $\mathrm{H}_{0}$

4. $\mathrm{t}_{1}=-0.409$ (for the WN parameter); $\mathrm{t}_{2}=2.231$ (for the WHT parameter); $t_{3}=1.754$ (for the VEG parameter); $\mathrm{t}_{4}=3.645$ (for the CIT parameter); $\mathrm{t} 5=4.082$ (for the APP parameter);

According to the above results, the null hypothesis $\left(\mathrm{H}_{0}\right.$ : $\left.\beta_{1}=0, \quad \beta_{2}=0, \quad \beta_{3}=0, \quad \beta_{4}=0\right)$ is rejected. Therefore, each independent variable is statistically significant.

In addition, the results have shown that the four variables (Wheat, Veggies, Citrus and Apples) explain 97\% of the variation of the dependent variable (Water Needed variable). Since $\mathrm{R}^{2}$ is greater than 80 percent, this means that Water Needed variable has been very well explained by the independent variables (Wheat, Veggies, Citrus, and apples in tons). This confirms the ANOVA results where the sum of squares regression (11639750.25) is higher than the sum of squares residuals (355541.4259) (shown in table 3 above).

Another hypothesis is proposed to further test the quality of the WN model. The new hypothesis is: at least one independent variable (Wheat, Veggies, Citrus or Apples) explains the dependent variable (Water Needed):

1. $\mathrm{H}_{0}: \beta_{1}=\beta_{2}=\beta_{3}=\beta_{4}=0$

$\mathrm{H}_{1}$ : At least one independent variable explains the dependent variable

2. $\alpha=0.05$

$\mathrm{F}^{*}=\mathrm{MSR} / \mathrm{MSE}=2909937.563 / 44442.678=65.476$

The degrees of freedom:

Vertical is $n-p=13-5=8$

Horizontal isp $-1=5-1=4$

From the table the critical value of $(\mathrm{F})$ is $\mathrm{F}=5.05$

Since $F^{*}=65.476>F$-critical $=5.05$, therefore; the null hypothesis is rejected.

A correlation matrix shows correlation coefficients between variables in a given model. Each cell in the table shows the correlation between two variables. A correlation matrix is used as a way to summarize data, and as an input into a more advanced analysis, and as a diagnostic for advanced analyses [18].

Table 4. Correlations.

\begin{tabular}{llllll}
\hline $\begin{array}{l}\text { Pearson } \\
\text { Correlation }\end{array}$ & WN & Wheat & Veggies & Citrus & Apples \\
\hline WN & 1.000 & 0.863 & 0.592 & 0.950 & 0.316 \\
Wheat & 0.863 & 1.000 & 0.533 & 0.886 & -0.071 \\
Veggies & 0.592 & 0.533 & 1.000 & 0.569 & -0.095 \\
Citrus & 0.950 & 0.886 & 0.569 & 1.000 & 0.130 \\
Apples & 0.316 & -0.071 & -0.095 & 0.130 & 1.000 \\
\hline
\end{tabular}

Reliability of Results

Four diagnostic tests for the WN model are discussed as follows:

1. The Durbin-Watson (DW)

2. The Normality Test

3. The Breusch-Pagan Test

4. The Koenker Test.

The Durbin-Watson (DW) test is conducted to detect Autocorrelation in the model. Autocorrelation (also called serial correlation), is the similarity of a time series over successive time intervals. Durbin-Watson (DW) should have a value from 0 to 4 . If DW is between 0 and 2, then there no autocorrelation, therefore, no need for a test. If DW is between 2 and 4, then there is a need to test for negative correlation.

In the WN Model the tested DW is at 2.833 (shown in table 5), "if the computed d value is closer to zero, there is an evidence of positive autocorrelation, but if it is closer to 4, there is an evidence of negative autocorrelation. Moreover, the closer the $d$ value is to 2 , the more the evidence is in favor of no autocorrelation" [19]. Therefore, since d computed is closer to 2 , it can safely be concluded that there is no autocorrelation. 
The Normality Test, through Skewness and Kurtosis, will determine whether the model will satisfy the conditions of normality of residuals. Kurtosis measures if there are outliers, and Skewness measures the lack of Symmetry [19]. The descriptive statistics are in table 5 below.

Table 5. Skewness and Kurtosis.

\begin{tabular}{lllll}
\hline & Skewness & & Kurtosis \\
\cline { 2 - 5 } & Statistic & Standard. Error & Statistic \\
\hline Wheat & 1.770 & 0.616 & 3.117 \\
Veggies & 1.817 & 0.616 & 4.381 & Standard Error \\
Citrus & 0.670 & 0.616 & -1.263 & 1.191 \\
Apples & 0.391 & 0.616 & -0.894 & 1.191 \\
Water Needed & 0.132 & 0.616 & -1.189 \\
\hline
\end{tabular}

To test for skewness in the model, the Standard Error of the Skewness is multiplied by 3 , if the statistical value of the Skewness is less than the number, then the errors are normally distributed. The same testing process applies to Kurtosis [19].

The values after multiplying by 3 :

Skewness $=1.848$

Kurtosis $=3.573$

Since one variable, Veggies, in Kurtosis has a statistic value higher than the multiplied Standard Error, a Q-Q plot is conducted to further investigate the distribution of the Veggies data [20].

The Q-Q plot or quantile-quantile (percentile) plot is a scatterplot graph that is used to help in understanding if a set of data come from the same distribution. The Q-Q takes the sample data and plots them against theoretical data. The more the data is plotted along a straight line the more normally distributed it is assumed to be [20].

After conducting the test, and as per figure 5 below, there is a normal distribution. This indicates that no problem with the Kurtosis, indicating that it is fairly linear although some points are above, and some are below.

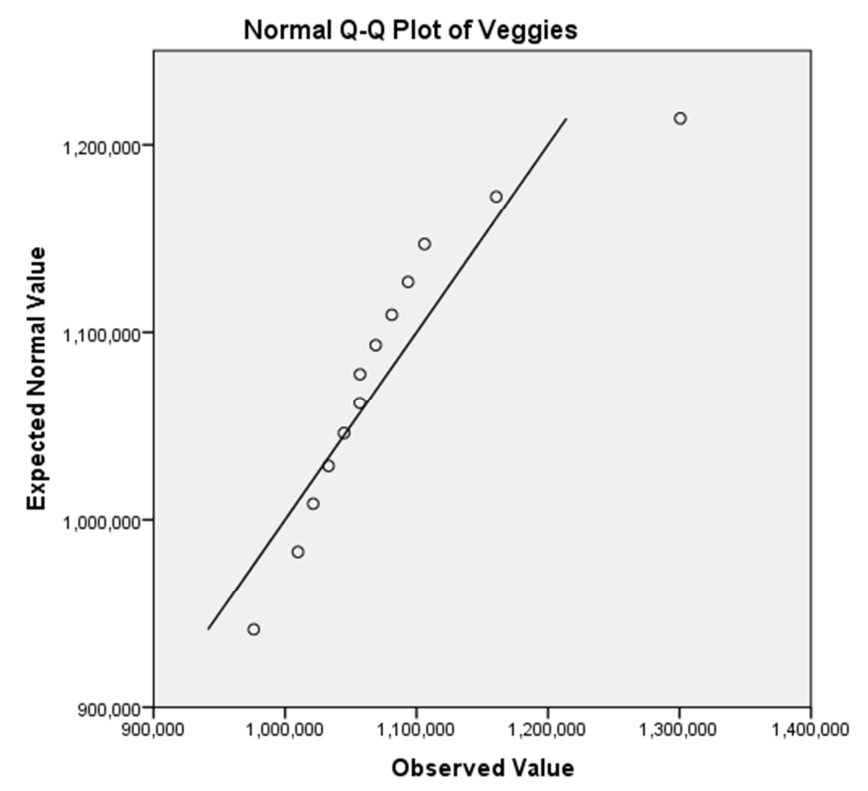

Figure 5. Normal QQ Plot for Veggies.

The final test is for measuring the presence of Heteroscedasticity using the Breusch-Pagan (BP) and
Koenker tests:

Heteroscedasticity exists when the standard errors of the variables, monitored over a specific amount of time, are not constant. The variables will "create a cone-like shaped as the variability of the dependent variable widens or narrows as the value of the independent variable increases" [15].

While heteroscedasticity does not cause bias in the coefficient estimates, it does make them less precise; lower precision increases the likelihood that the coefficient estimates are further from the correct population value. It is important to mention that Homoscedasticity is the exact opposite or inverse of heteroscedasticity, therefore homoscedasticity shows that specific dependent variables variability is equal across the values of the independent variable. Results are shown in table 6 below.

Table 6. Breusch-Pagan (BP) and Koenker Tests.

\begin{tabular}{lll}
\hline & Breusch-Pagan (BP) & Koenker \\
\hline Chi Square $(\mathrm{df}=\mathrm{P})$ & 25.624 & 10.31 \\
Sig. Level of Chi Square $(\mathrm{df}=\mathrm{P})$ & 0 & 0.035 \\
Regression SS & 51.249 & \\
Residual SS & 13.052 & \\
R-Square & 0.797 & \\
\hline
\end{tabular}

**Significance Level: $5 \%$.

**N=4 (which represents all Agricultural Produce).

The above table shows the results of the two methods that test for the existence of heteroscedasticity. The first method, the Breusch-Pagan (BP) test and the second method the Koenker test, both show the Chi-Square values, thus following the Chi-Square distribution. The probability values for both are greater than the level of significance 5\%, therefore, heteroscedasticity not present, this means that the Null Hypothesis of homoscedasticity is not rejected, thus; the residuals are homoscedastic.

The four diagnostic tests, Normality, Durbin-Watson, Koenker, and Breusch-Pagan, verify that the model is accurate and reliable.

\section{Conclusion}

The Arabian orient from the end of World War II on has been boiling with conflicts, the underlying reason ever since, natural resources. The vassal states created by the French and the British after their victory in the Great War had their borders drawn on the premise of distributing this 
wealth. However; priorities in the region are starting to shift. With the rising prices, diminishing reserves of oil and the discovery of larger deposits in other regions of the world, the dependence on solar and renewable energy sources is gaining an equivalent strategic importance, water is becoming a major player in the region's politics, and it is the new strategic asset. Moreover, Water is the source of all living things. Throughout all phases of human history civilizations have thrived near and around water resources. Conflicts have always erupted to maintain control over and access to water sources. The ancestors of the Arabs came from Yemen, with a flourishing kingdom, the famous kingdom of Saba, they thrived around water resources.

This paper utilized a regression model in determining the level of needed water to produce wheat, veggies, citrus and apples. The regression model gave the following results, $\mathrm{R}^{2}=0.97 \%$, t-test with $\mathrm{t}_{1}=-0.409$ (for the $\mathrm{WN}$ parameter); $\mathrm{t}_{2}=2.231$ (for the WHT parameter); $\mathrm{t}_{3}=1.754$ (for the VEG parameter); $t_{4}=3.645$ (for the CIT parameter); $t_{5}=4.082$ (for the APP parameter); F-test $=65.476$, Durbin-Watson $(D W)=2.833$, Normality test with Skewness $=1.848$ and Kurtosis=3.573, Breusch-Pagan test Chi Square=25.624, and Koenker Chi Square=10.31.

The above results reveal that the model is accurate with a linear relationship between water and the agricultural produce. That is, for every ton of wheat produced .14 MCM of water is needed, for every ton of veggies produced .002 MCM of water is needed, for every ton of citrus produced $.006 \mathrm{MCM}$ of water is needed, and for every ton of apple produced $.035 \mathrm{MCM}$ of water is needed.

\section{Recommendations}

Based on the findings of the study, it is recommended that Lebanon should embark on the plantation of veggies and citrus since the model reflected that the level of needed water per ton is lower than the rest of the crops. This could be utilized for water sustainability policies in order to conserve water, and to increase the efficiency of water use for irrigation in Lebanon. Moreover, Lebanon should move away from high concentration water consuming crops to lower consuming crops, such as cereal, towards veggies and citrus. And finally, Lebanon can adopt new techniques to save water. An example is apples and citrus, where starting from the time of seedlings, apples and citrus can be adapted to extract the needed water from moisture from soil based on continuous ploughing and rain fed irrigation during winter time.

\section{Limitations}

Unfortunately, in Lebanon the Ministry of Energy and Water has very scarce information regarding the subject at hand. In addition, upon trying to solicit data from the Litany authority (is the authority for the largest river in LebanonLitany); soliciting data was a very hard task. Obtaining the required information on Lebanese water systems, dams, networks, and projects from the governmental bodies has almost been impossible.

A regression model has been used covering 4 main crops only due to time and resource constraints, where in reality; more crops should have been added to reflect the real level of needed water in Lebanon. However, the paper at hand could be used as a prelude to future studies related to the same subject.

\section{References}

[1] History of Ancient Arabia before the rise of Islam and the Caliphate. (n. d.). Retrieved June 08, 2018, from https://www.timemaps.com/encyclopedia/history-of-arabia/.

[2] Byblos, Well (2). (n. d.). Retrieved June 08, 2018, from https://www.livius.org/pictures/lebanon/jubayl-byblos/bybloswell/byblos-well-2/.

[3] United Nations Department of Economic and Social Affairs (UN DESA). (2017). World population Report. Retrieved June 09, 2018, from https://www.un.org/development/desa/en/news/population/wor ld-population-prospects-2017.html.

[4] Water in Lebanon Strategic Management data National assessment Matrix (2012). UNESCWA. Retrieved October 29, 2018 from https://unstats.un.org/unsd/envaccounting/workshops/Beirut20 12/Beirut2012-11.PDF.

[5] Nasser, C. Beydoun (2002, September 20). Country has right to Wazzani water. The Daily Star. Retrieved October 16, 2018, from http://www.dailystar.com.lb/News/Lebanon-News/2002/Sep20/19161-beydoun-country-has-right-to-wazzani-water.ashx.

[6] Al Farawati, R., Al Maradni, A., Basaham, A., \& El Sayed, M. (2008). Reclaimed Municipal Wastewater used for the Irrigation of Green Areas in Jeddah: 1 - Chemical Characteristics. Retrieved June 09, 2018, from https://www.kau.edu.sa/Files/320/Researches/51959_22091.p dfIbrahim Abd El Al (1959). Retrieved June 09, 2018, from https://www.ibrahimabdelal.org/news.html.

[7] Daou, R., \& Mikhael, M. (2017, August 25). Lebanon's Paradox: Water is Abundant yet Scarce (Rep.). Retrieved December 14, 2018, from http://blog.blominvestbank.com/wpcontent/uploads/2017/08/Lebanon's-Paradox-Water-isAbundant-yet-Scarce.pdf.

[8] Killgore, A. I. (2006, September/October). For Israel, Southern Lebanon Means the Litani River. Retrieved October 18, 2018, from https://www.wrmea.org/006-septemberoctober/for-israel-southern-lebanon-means-the-litaniriver.html.

[9] Abed El Al, I. (1959). The Litany Project. Ministry of Energy and Water (MOEW), Beirut- Lebanon.

[10] Assessment of Groundwater Resources of Lebanon. (2014). Retrieved June 12, 2018, from ttp://www.lb.undp.org/content/dam/lebanon/docs/Energy and Environment/Publications/Assessment of Groundwater Resources of Lebanon.pdf. 
[11] Shlomi Dinar and Ariel Dinar on Recent Developments in the Literature on Conflict Negotiation and Cooperation over Shared International Fresh Waters. (2003). Natural Resources Journal, 43 (4), 1217-1287. Retrieved from http://www.jstor.org/stable/24888900.

[12] Fisk, R. (2018, June 08). Lebanon's mountains are being wiped from the map - but does anyone care? Retrieved October 29, 2018, from https://www.independent.co.uk/voices/lebanon-mountainsenvironmental-destruction-quarrying-construction-industrybeirut-why-a8388006.html.

[13] Houri, A., \& El Jeblawi, S. (2007). Water quality assessment of Lebanese coastal rivers during dry season and pollution load into the Mediterranean Sea. Retrieved October 26, 2018, from https://pdfs.semanticscholar.org/c2e4/63009f9043d28cc906742 3aab2e9cacafed8.pdf.

[14] Water Conservation Tips. (n.d.). Retrieved October 07, 2018 from https://www.nwc.com.sa/English/Community-andEnvironment/Water-value/Water-ConservationTips/Pages/default.aspx.
[15] H. Stock and M. W. Watson, Introduction to Econometrics ( $3^{\text {rd }}$. edition), Addison-Wesley, 2017.

[16] Trochim, W. M., \& Donnelly, J. P. (2006). The research methods knowledge base (3rd ed.). Cincinnati, OH: Atomic Dog.

[17] Gravetter, F., \& Wallnau, L. (2014). Essentials of statistics for the behavioral sciences (8th ed.). Belmont, CA: Wadsworth.

[18] Bock, T. (2019). What is a correlation matrix. Displayer. Retrieved September 25, 2019 from https://www.displayr.com>what-is-a-correlation-matrix.

[19] Hamdar, Bassam, Khaled Hamdan, and Hala Kinawi (2017). "The Economic Implications of Enforcing the Common Agricultural Policy (CAP) in the Arab Region" International Journal of Economics, Commerce and Management ((IJECM), vol 5, No. 7, July 15.

[20] Field, A. (2009). Discovering statistics using SPSS. London: SAGE. 